\title{
Cytoreductive Strategies in the Treatment of Carcinomatosis of Colorectal Origin: Results of a Transdisciplinary National Survey
}

\author{
Angela W. Chan ${ }^{1}$, Gitonga Munene ${ }^{4}$, Joel Weaver ${ }^{1}$, Anthony MacLean ${ }^{1}$, Jay Easaw ${ }^{2}$, \\ Gilaad G. Kaplan ${ }^{3}$, Robyn D. Parker ${ }^{1}$ and Elijah Dixon ${ }^{*}, 1$ \\ ${ }^{I}$ Division of General Surgery, ${ }^{2}$ Department of Oncology, ${ }^{3}$ Division of Gastroenterology, University of Calgary, Canada \\ ${ }^{4}$ Department of General Surgery, University of Tennessee Health Science Center, Memphis, TN, USA
}

\begin{abstract}
Background: Many patients are not referred to centers specializing in the treatment of peritoneal malignancies. This survey evaluates Canadian physician attitudes toward the role of cytoreduction in treating colorectal carcinomatosis.

Methods: A discrete-choice questionnaire containing a hypothetical scenario surveyed physician preferences for the management of colorectal carcinomatosis.

Results: Three mail-outs yielded a 49\% response rate (217 responses). For synchronous colorectal carcinomatosis, $28.6 \%$ favoured cytoreduction with or without HIPEC plus systemic chemotherapy, and 18.9\% cytoreduction with HIPEC alone. For metachronous carcinomatosis, $27.4 \%$ favoured cytoreduction with or without HIPEC plus systemic chemotherapy, and $14.9 \%$ cytoreduction with HIPEC alone. For metachronous carcinomatosis with a single liver metastasis, $24.6 \%$ favoured cytoreduction with or without HIPEC plus systemic chemotherapy, and $4.6 \%$ cytoreduction with HIPEC alone.

Conclusion: Most physicians do not favor cytoreduction in the treatment of colorectal carcinomatosis. Knowledge translation strategies are needed to improve awareness regarding its utility in specific clinical scenarios.
\end{abstract}

Keywords: Appendiceal cancer, carcinomatosis, colorectal cancer, heated intraperitoneal chemotherapy.

\section{INTRODUCTION}

Spratt et al. first described the use of intraperitoneal chemotherapy in the management of peritoneal malignancies $[1,2]$. Since then, there have been significant advances in this treatment strategy, including data from a phase 3 study that demonstrated that patients randomized to cytoreductive surgery (CRS) with HIPEC versus adjuvant systemic therapy alone had improved overall survival compared to systemic chemotherapy alone [3, 4]. Patients with a low burden of disease have a better prognosis and recently, institutional reports have shown median survival of up to 62 months in well-selected patients [5]. However, a minority of the approximately 15,000 patients per year with colorectal carcinomatosis in the US are referred to specialized centers for this multimodal approach [6].

To further understand and identify potential barriers to referral, a survey was conducted to assess the prevailing attitude towards CRS for the treatment of colorectal carcinomatosis. The aim of this study was to investigate the views of the main groups of physicians dealing with this patient population: medical oncologists, gastroenterologists, general surgeons, colorectal surgeons and surgical oncologists in Canada regarding the role of CRS in colorectal carcinomatosis.

*Address correspondence to this author at the Foothills Medical Centre, 1403 - 29th Street NW, Calgary, Alberta, T2N 2T9, Canada; Tel: (403) 944-3045; Fax: (403) 944-3502;

E-mail: Elijah.Dixon@albertahealthservices.ca

\section{METHODS}

\section{Inclusion and Exclusion Criteria}

A list of all practicing physicians in General Surgery, Gastroenterology and Medical Oncology was obtained from the Royal College of Physicians and Surgeons of Canada Directory of Fellows [7]. We identified 88 surgical oncologists and 64 practicing colorectal surgeons from the Canadian Society of Surgical Oncology (CSSO) and Canadian Society of Colon and Rectal Surgeons (CSCRS) website, respectively. We surveyed all members of the CSSO and CSCRS. We randomly sampled 100 general surgeons, 100 gastroenterologists, and 100 medical oncologists. Each clinician was assigned a number. Using a random sequence generator we developed our sample populations. There was no duplication between general surgeons, surgical oncologists and colorectal surgeons. Surveys were coded with the physician's assigned number to track who responded while maintaining anonymity.

\section{Survey Content and Distribution}

The original survey consisted of colon, gastric, pancreatic and appendiceal cancer clinical scenarios. In this paper, we will present the data for colon cancer. The case patient in our study was a healthy 46 year old female, with no contraindication to surgical and/or medical intervention(s). Respondents were asked to indicate which type of therapy would represent the current standard of care (Fig. 1), as well as demographic variables such as their current location of practice, years of practice and age (Table 1). 


\begin{tabular}{|l|ccc|}
\hline \multicolumn{1}{|c|}{ Scenarios } & \multicolumn{3}{|c|}{ Intervention } \\
\hline 1. Cecal adenocarcinoma with a negative staging work-up. & A B C D E F G \\
\hline $\begin{array}{l}\text { 2. Cecal adenocarcinoma with an isolated liver metastasis to the left lateral } \\
\text { segment (synchronous disease) }\end{array}$ & A B C D E F G \\
\hline $\begin{array}{l}\text { 3. Cecal adenocarcinoma resected two years previously, now presenting } \\
\text { with an isolated liver metastasis to the left lateral segment. }\end{array}$ & A B C D E F G \\
\hline $\begin{array}{l}\text { 4. Cecal adenocarcinoma with bilobar, multisegment liver metastases. } \\
\text { 5. Cecal adenocarcinoma with carcinomatosis, and no distant metastatic } \\
\text { disease (synchronous disease) }\end{array}$ & A B C D E F G C D E F G \\
\hline $\begin{array}{l}\text { 6. Cecal adenocarcinoma resected two years previously, now with } \\
\text { carcinomatosis, and no distant metastatic disease. }\end{array}$ & A B C D E F G \\
\hline $\begin{array}{l}\text { 7. Cecal adenocarcinoma resected two years previously, now with } \\
\text { carcinomatosis and a single liver metastasis. }\end{array}$ & A B C D E F G \\
\hline
\end{tabular}

For all scenarios listed below, the patient is an otherwise healthy 46 year old female, with no contra-indication to surgical and/or medical interventions. Please indicate which option provided best represents the current standard of care.

List of interventions:

A. Surgical resection alone

B. Systemic therapies alone

C. Combination systemic and surgical therapies

D. Cytoreductive surgical therapies

E. Cytoreductive surgical therapies with intraperitoneal chemotherapy.

F. Cytoreductive surgical therapies (with or without intraperitoneal chemotherapy), plus systemic therapies.

G. Palliation

Fig. (1). Colon cancer clinical scenarios.

Table 1. Demographic Characteristics of All Survey Respondents

\begin{tabular}{|c|c|}
\hline Characteristic & Number of Responses (\%)* \\
\hline \hline $\begin{array}{c}\text { Current location of practice } \\
\text { (population size) }\end{array}$ & 171 responses \\
\hline Urban (>50000) & $74(43.3)$ \\
\hline $\begin{array}{c}\text { Urban teaching } \\
(>50000 \text { with medical school) }\end{array}$ & $85(49.7)$ \\
\hline Rural (10000-50000) & $11(6.4)$ \\
\hline Rural remote $(<10000)$ & $1(0.6)$ \\
\hline Years of practice & 168 responses \\
\hline$<5$ years & $27(16.1)$ \\
\hline $5-10$ years & $41(24.4)$ \\
\hline $10-20$ years & $48(28.6)$ \\
\hline$>20$ years & $52(31.0)$ \\
\hline Age (years) & 162 responses \\
\hline $30-35$ years & $11(6.8)$ \\
\hline $35-40$ years & $26(16.0)$ \\
\hline $40-50$ years & $62(38.3)$ \\
\hline $50-60$ years & $43(26.5)$ \\
\hline$>60$ years & $20(12.3)$ \\
\hline Numbers do not add to 175 respondents because not all respondents answered every
\end{tabular}

*Numbers do not add to 175 respondents because not all respondents answered every question.

In January 2010, the survey was mailed along with a cover letter stating the objectives and a self addressed stamped envelope to the colorectal surgeons, gastroenterologists, medical oncologists and general surgeons. The surgical oncologists were e-mailed because at the time, we only had access to a nationwide e-mail list. A second mail-out was completed in May-June 2010, where all five specialties were mailed the same documents. This was followed by a third mail-out in September 2010. The final surveys were collected on 17th December 2010. Descriptive analysis was performed. Where appropriate the Chi Square and Fischer Exact tests were used.

This project was approved by the University of Calgary Conjoint Health Research Ethics Board and meets TriCouncil guidelines for ethical research.

\section{RESULTS}

\section{Response Rate}

On the first mail-out, we received 111 out of 452 surveys (25\%) (Fig. 2). Those who did not respond were re-mailed the survey. Some responded but did not complete the survey because they were retired or not practicing gastroenterological oncology. Some questionnaires were returned to our address, because those physicians had relocated. These people were removed from the study and replaced one-to-one with new physicians who practiced the same specialty. Physicians for the second iteration were chosen randomly using the number generator.

On the second mail-out, we received 168 out of 440 surveys $(38 \%)$. To improve response rates, we decided to mail rather than e-mail the surgical oncologists. 76 of the original 88 addresses were obtained from the College of Physicians and Surgeons provincial websites. We did not replace the 12 missing surgical oncologists. A third mail-out was sent out achieving a response rate of 217 out of 440 


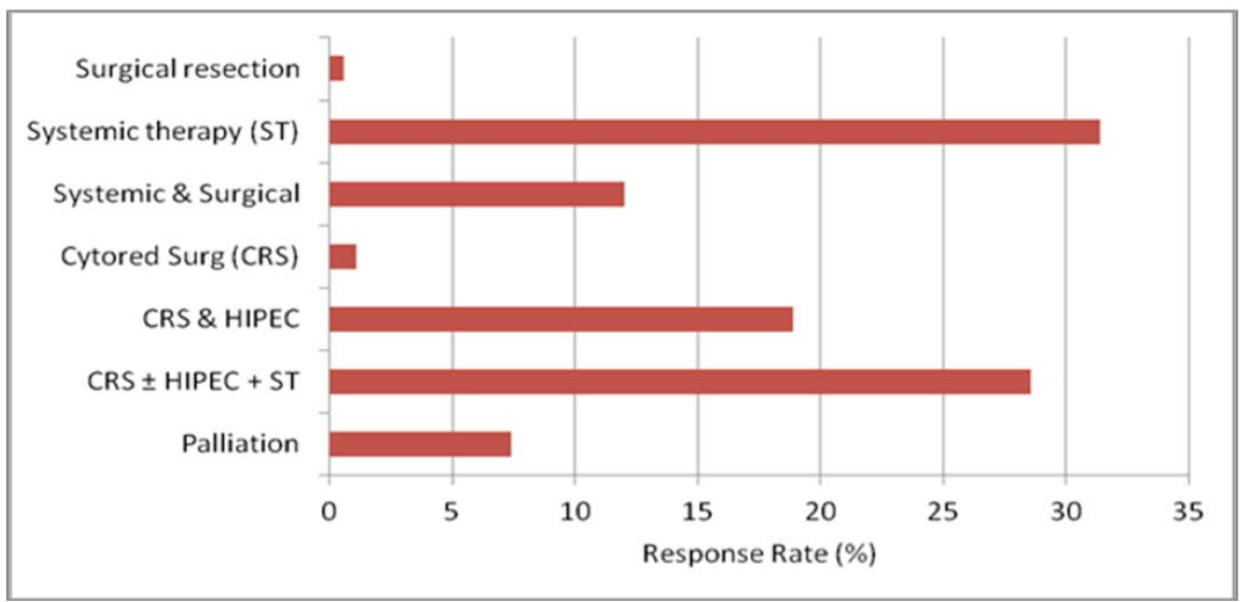

Fig. (2). Total response rates among all specialties for cecal adenocarcinoma with carcinomatosis, and no distant metastatic disease.

surveys (49\%). Of the 217 respondents, only 175 clinicians completed all the questions on colon cancer, our area of interest in this study. Surgical oncologists and colorectal surgeons had the highest response rates.

\section{Demographics}

Table 1 shows the demographic characteristics of the respondents. $93 \%$ of the respondents were from urban areas, most of who practiced in urban teaching hospitals. The subspecialty representation in the respondents was equally divided, whereas years of practice and age were not equally represented amongst each category. $31 \%$ of physicians in our study have practiced over twenty years and $38 \%$ were $40-50$ years old.

\section{Cecal Adenocarcinoma with Synchronous Carcinomatosis}

Fig. (2) shows the respondents' views on the most appropriate therapy for patients with synchronous carcinomatosis. $31.4 \%$ of respondents favored systemic therapy alone, $28.6 \%$ cytoreduction with or without HIPEC plus systemic chemotherapy, and $18.9 \%$ cytoreduction with HIPEC alone. Although respondents favored systemic therapies as compared to other options, $50 \%$ of the overall group seemed to favor some form of cytoreductive approach.

To determine differences in views towards cytoreductive surgery, options D, E and F were combined as favoring cytoreductive surgery. Table 2 shows subspecialty views on cytoreductive surgery for synchronous colorectal metastases. Differences were observed between specialties $(\mathrm{p}<0.01)$ with $65 \%$ of colorectal surgeon favoring cytoreductive approaches compared to only $33.3 \%$ of medical oncologists. No significant differences were detected based on the remaining demographic variables.

\section{Cecal Adenocarcinoma with Metachronous Carcinomatosis}

Fig. (3) shows the respondents' views on the most appropriate therapy for patients with metachronous colorectal carcinomatosis. The majority of respondents favored systemic therapy alone, however, the entire group was evenly divided between systemic therapies or cytoreductive strategies: $49 \%$ vs $44 \%$ respectively. Amongst specialties, colorectal surgeons expressed most preference for cytoreduction, as $55 \%$ felt there was a role. $(\mathrm{p}<0.05)$ (Table 2).
Table 2. Response Rates by Specialty

\begin{tabular}{|c|c|c|}
\hline \multirow[b]{2}{*}{ Specialty } & \multicolumn{2}{|c|}{ Role of Cytoreduction } \\
\hline & $\begin{array}{c}\text { Yes } \\
\text { (Options DEF) } \\
\text { \% Response }\end{array}$ & $\begin{array}{c}\text { No } \\
\text { (Options ABCG) } \\
\text { \% Response }\end{array}$ \\
\hline \multicolumn{3}{|c|}{$\begin{array}{l}\text { For cecal adenocarcinoma with carcinomatosis, } \\
\text { and no distant metastatic disease (synchronous disease) }\end{array}$} \\
\hline Surgical Oncology (SO) & 51.3 & 48.7 \\
\hline General Surgery (GS) & 41.2 & 58.8 \\
\hline Colorectal Surgery (CR) & 65.0 & 35.0 \\
\hline Gastroenterology (GI) & 46.4 & 53.6 \\
\hline Medical Oncology (MO) & 33.3 & 66.7 \\
\hline \multicolumn{3}{|c|}{$\begin{array}{l}\text { For cecal adenocarcinoma resected two years previously, } \\
\text { now with carcinomatosis and no distant metastatic disease. }\end{array}$} \\
\hline Surgical Oncology (SO) & 48.7 & 51.3 \\
\hline General Surgery (GS) & 38.2 & 61.8 \\
\hline Colorectal Surgery (CR) & 55.0 & 45.0 \\
\hline Gastroenterology (GI) & 50.0 & 50.0 \\
\hline Medical Oncology (MO) & 21.2 & 78.8 \\
\hline \multicolumn{3}{|c|}{$\begin{array}{l}\text { For cecal adenocarcinoma resected two years previously, } \\
\text { now with carcinomatosis and a single liver metastasis. }\end{array}$} \\
\hline Surgical Oncology (SO) & 33.3 & 66.7 \\
\hline General Surgery (GS) & 35.3 & 64.7 \\
\hline Colorectal Surgery (CR) & 35.0 & 65.0 \\
\hline Gastroenterology (GI) & 30.0 & 70.0 \\
\hline Medical Oncology (MO) & 15.2 & 84.8 \\
\hline
\end{tabular}

\section{Carcinomatosis with a Single Liver Metastases}

Fig. (4) shows the respondents views on the most appropriate therapy for patients with a metachronous colorectal carcinomatosis and a single liver metastases. Almost $50 \%$ of respondents favoured systemic therapy. No significant differences were noted between various specialties (Table 2 ). 


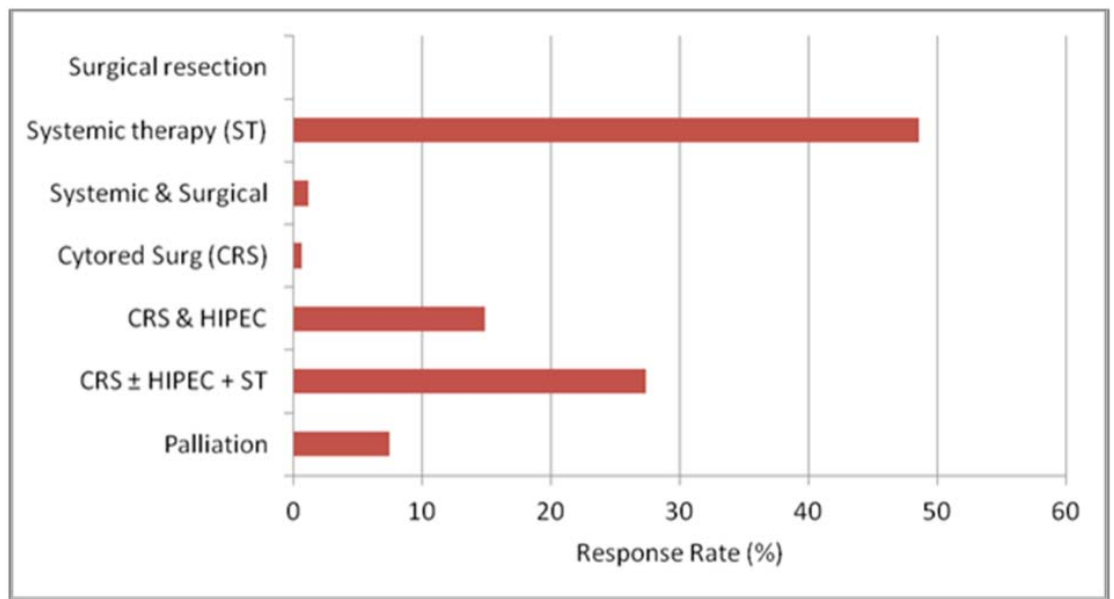

Fig. (3). Total response rates among all specialties for cecal adenocarcinoma resected two years previously, now with carcinomatosis, and no distant metastatic disease.

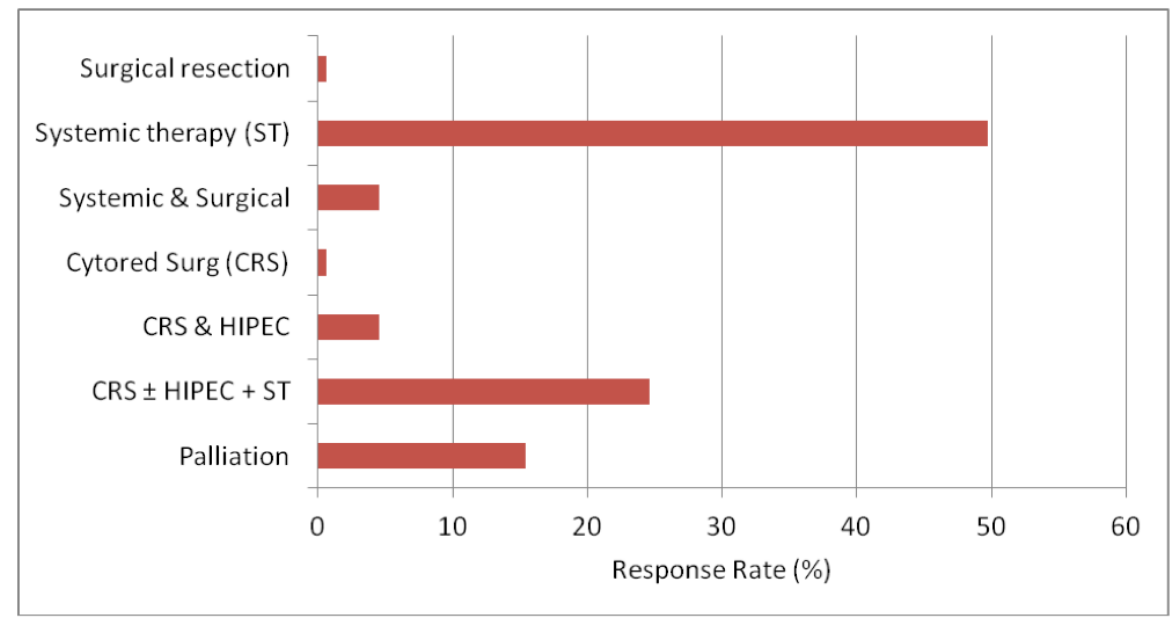

Fig. (4). Total response rates among all specialties for cecal adenocarcinoma resected two years previously, now with carcinomatosis and a single liver metastasis.

\section{DISCUSSION}

Approximately $10 \%$ of patients with colorectal cancer will have peritoneal disease as an early or late manifestation of their disease [8]. This represents approximately 15,000 and 1,200 new patients a year in US and Canada respectively [8]. The natural history of patients with peritoneal carcinomatosis is poor, with median survival ranging from 6 months without treatment to 23.7 months with the latest multiagent chemotherapeutic regimens $[8,9]$. A multimodal approach that includes cytoreduction with hyperthermic intraperitoneal chemotherapy and adjuvant chemotherapy has resulted in improvements of reported median survival from 13 months to 29 months, and 5yr overall survival of 11$19 \%[3,4]$. Patients who have complete cytoreduction have considerably improved outcomes with median survival of 28 to 60 months and 5-year overall survival ranging from $22 \%$ to $49 \%[3,4,10,11]$. However, it is estimated that only a small percentage of these patients undergo this potential life saving procedure per year [6].

$\mathrm{CRS} \pm \mathrm{HIPEC}$ procedures carry significant morbidity and mortality; therefore judicious selection of patients by clinicians is important. Overall health and extent of disease are the two most common prognosticators for a favourable outcome. Good candidates for surgery are those who are aged 65 years or younger, not morbidly obese (BMI >40) with good nutritional status [12], and an Eastern Cooperative Oncology Group (ECOG) score of 2 or less. One study considered patients aged up to 70 for the procedure [13]; older patients with localized peritoneal carcinomatosis and good general health (absence of severe cardiopulmonary or renal failure) should be assessed on a case by case basis.

In terms of disease burden, patients should not have extraperitoneal metastases, massive retroperitoneal lymphadenopathy or extensive involvement of the small bowel or mesentery. A Peritoneal Cancer Index (PCI) score $<20$ is amenable to surgery $[14,15]$. For colorectal carcinomatosis, one to three resectable liver metastases is reasonable for cytoreductive surgery [16]. Ideally surgery should achieve a completeness of cytoreduction score $(\mathrm{CC}) \leq$ 1 to achieve optimal outcome, meaning that residual tumour nodules are $\leq 2.5 \mathrm{~mm}$ in diameter. Various studies have shown that intraperitoneal chemotherapeutic agents can effectively penetrate to a maximum depth of $2-3 \mathrm{~mm}$ [13]. 
In this study we have shown that most physicians involved in the care of patients with colorectal peritoneal carcinomatosis do not consider CRS + HIPEC as a viable option for the treatment of this disease. Only $47 \%$ and $44 \%$ of physicians thought there was a role for CRS in patients with synchronous and metachronous colorectal carcinomatosis respectively. An even smaller group considered CRS an option in patients with CPC and liver metastases. There were significant differences in views regarding CRS across various specialties. Colorectal surgeons and surgical oncologists were more likely to view CRS as an option for patients with CPC. Interestingly, medical oncologists showed the least preference for CRS.

The reasons that cytoreductive surgery is not frequently seen as a viable treatment option in colorectal peritoneal carcinomatosis (CPC) are unclear. While this study was not designed to address this issue, we believe that the paucity of level 1 data available to support this approach, and the fact that currently few centers perform CRS influence physicians attitudes. There may also be a perception that CRS is associated with unacceptable morbidity and mortality rates, though this is unfounded. The morbidity associated with CRS ranges from 9 to $44 \%$, while mortalities range from 0 $11 \%$ [17-19]. Studies on the quality of life following CRS have also shown that patients achieve a good and sustained quality of life after a period of time [20].

There are several limitations to this study. First, the response rate was $49 \%$, which is an acceptable response rate for most surveys in the medical literature. As with most surveys there is an inherent response bias which is evident in the demographic variability of the responders. Physicians in urban teaching centers tend to respond more frequently to physician surveys; therefore, this survey may not be reflective of actual physician views nationwide. Second, this study does not evaluate the actual referral rate; a physician who does not think there is a role for CRS may still refer a patient to a cytoreduction center and vice versa. Third, the information about the hypothetical patient does not include the location and volume of the peritoneal carcinomatosis. Finally, there might be geographical and country-specific differences in attitudes regarding CRS so this may not be generalizable to other regions.

Only a small minority of physicians involved in the treatment of colorectal carcinomatosis view CRS with HIPEC as an appropriate treatment option for their patients. The cognitive and behavioral process a physician passes through when confronted with new information are: awareness of new information; agreement with the new information; adoption of the new information into practice; and adherence to using the new information on an ongoing basis [21]. To address these prevailing attitudes, education and dissemination of information on CRS may be effective to counteract this prevailing view. Awareness and agreement between the specialties involved in the treatment of these complex diseases will result in higher referral and potentially increase the number of patients undergoing CRS+ HIPEC.

\section{CONFLICT OF INTEREST}

The authors confirm that this article content has no conflict of interest.

\section{ACKNOWLEDGEMENTS}

Dr. Dixon is supported through a Population Health Investigator award from the Alberta Heritage Foundation for Medical Research (AHFMR) and a New Investigator award from the Canadian Institute of Health Research.

\section{REFERENCES}

[1] Spratt JS, Adcock RA, Muskovin M, Sherrill W, McKeown J. Clinical delivery system for intraperitoneal hyperthermic chemotherapy. Cancer Res 1980; 40: 256-60.

[2] Spratt JS, Adcock RA, Sherrill W, Travathen S. Hyperthermic peritoneal perfusion system in canines. Cancer Res 1980; 40: 2535.

[3] Verwaal VJ, Bruin S, Boot H, van SG, van TH. 8-year follow-up of randomized trial: cytoreduction and hyperthermic intraperitoneal chemotherapy versus systemic chemotherapy in patients with peritoneal carcinomatosis of colorectal cancer. Ann Surg Oncol 2008; 15: 2426-32.

[4] Yan TD, Black D, Savady R, Sugarbaker PH. Systematic review on the efficacy of cytoreductive surgery combined with perioperative intraperitoneal chemotherapy for peritoneal carcinomatosis from colorectal carcinoma. J Clin Oncol 2006; 20(24): 4011-9.

[5] Elias D, Lefevre JH, Chevalier J, et al. Complete cytoreductive surgery plus intraperitoneal chemohyperthermia with oxaliplatin for peritoneal carcinomatosis of colorectal origin. J Clin Oncol 2009; 27: 681-5.

[6] Esquivel J. Current status of colorectal cancer with peritoneal carcinomatosis. Ann Surg Oncol 2010; 17: 1968-9.

[7] Directory of Fellows. Royal College of Physicians and Surgeons of Canada. Available at: http://rcpsc.medical.org/Directory/ [Accessed: Dec 31, 2009].

[8] Jayne DG, Fook S, Loi C, Seow-Choen F. Peritoneal carcinomatosis from colorectal cancer. Br J Surg 2002; 89: 1545-50.

[9] Sadeghi B, Arvieux C, Glehen O, et al. Peritoneal carcinomatosis from non-gynecologic malignancies: results of the EVOCAPE 1 multicentric prospective study. Cancer 2000; 88: 358-63.

[10] Hamilton T, Lanuke K, Mack LA, Temple WJ. Long-term followup in the treatment of peritoneal carcinomatosis. Am J Surg 2011; 201: 650-4.

[11] Bretcha-Boix P, Farre-Alegre J, Sureda M, Dussan C, Perez Ruixo JJ, Brugarolas MA. Cytoreductive surgery and perioperative intraperitoneal chemotherapy in patients with peritoneal carcinomatosis of colonic origin: outcomes after 7 years' experience of a new centre for peritoneal surface malignancies. Clin Transl Oncol 2010; 12: 437-42.

[12] Sugarbaker PH. Cytoreductive surgery plus hyperthermic perioperative chemotherapy for selected patients with peritoneal metastases from colorectal cancer: a new standard of care or an experimental approach? Gastroenterol Res Pract 2012; 2012: 9.

[13] Losa F, Barrios P, Salazar R, et al. Cytoreductive surgery and intraperitoneal chemotherapy for treatment of peritoneal carcinomatosis from colorectal origin. Clin Transl Oncol 2013 [Epub ahead of print].

[14] Elias D, Quenet F, Goere D. Current status and future directions in the treatment of peritoneal dissemination from colorectal carcinoma. Surg Oncol Clin N Am 2012; 21: 611-23.

[15] Sugarbaker PH, Ryan DP. Cytoreductive surgery plus hyperthermic perioperative chemotherapy to treat peritoneal metastases from colorectal cancer: standard of care or an experimental approach? Lancet Oncol 2012; 13: e362-9.

[16] Macri A. Selection of patients and staging of peritoneal surface malignancies. World J Gastrointest Oncol 2010; 2: 31-5.

[17] Levine EA, Stewart JH, Russell GB, Geisinger KR, Loggie BL, Shen P. Cytoreductive surgery and intraperitoneal hyperthermic chemotherapy for peritoneal surface malignancy: experience with 501 procedures. J Am Coll Surg 2007; 204: 943-53.

[18] Mohamed F, Moran BJ. Morbidity and mortality with cytoreductive surgery and intraperitoneal chemotherapy: the importance of a learning curve. Cancer J 2009; 15: 196-9.

[19] Cao C, Yan TD, Black D, Morris DL. A systematic review and meta-analysis of cytoreductive surgery with perioperative intraperitoneal chemotherapy for peritoneal carcinomatosis of colorectal origin. Ann Surg Oncol 2009; 16: 2152-65. 
[20] McQuellon RP, Loggie BW, Fleming RA, Russell GB, Lehman $\mathrm{AB}$, Rambo TD. Quality of life after intraperitoneal hyperthermic chemotherapy (IPHC) for peritoneal carcinomatosis. Eur J Surg Oncol 2001; 27: 65-73.
[21] Pathman DE, Konrad TR, Freed GL, Freeman VA, Koch GG. The awareness-to-adherence model of the steps to clinical guideline compliance. The case of pediatric vaccine recommendations. Med Care 1996; 34: 873-89.

(C) Chan et al.; Licensee Bentham Open.

This is an open access article licensed under the terms of the Creative Commons Attribution Non-Commercial License (http://creativecommons.org/licenses/by-nc/3.0/) which permits unrestricted, non-commercial use, distribution and reproduction in any medium, provided the work is properly cited. 